\title{
A 1.8 V Gm-C Highly Tunable Low Pass Filter for Sensing Applications
}

\author{
J. Pérez-Bailón \\ Group of Electronic Design (GDE) \\ University of Zaragoza \\ Zaragoza, Spain \\ jorgepb@unizar.es \\ J. Ramírez-Angulo \\ Klipsch School of Electrical and \\ Computer Engineering \\ New Mexico State University \\ Las Cruces, NM, USA \\ jairamir@nmsu.edu
}

\author{
B. Calvo \\ Group of Electronic Design (GDE) \\ University of Zaragoza \\ Zaragoza, Spain \\ becalvo@unizar.es
}

\author{
N. Medrano \\ Group of Electronic Design (GDE) \\ University of Zaragoza \\ Zaragoza, Spain \\ nmedrano@unizar.es
}

\begin{abstract}
This paper presents a fully integrated, first-order Low Pass Filter with 2-tuning points giving a wide versatility to the filter. It allows for a fine/thick tuning with a cutoff frequency that spans over several orders of magnitude, from $220 \mathrm{mHz}$ to $39.1 \mathrm{kHz}$. The $\mathrm{G}_{\mathrm{m}}-\mathrm{C}$ filter proposed is designed in a $180 \mathrm{~nm}$ CMOS technology with a total power consumption of $1.08 \mu \mathrm{W}$ for a $1.8 \mathrm{~V}$ power supply and a dynamic range up to $73 \mathrm{~dB}$. The proposed filter is a very competitive solution compared with previously reported works, meeting the requirements for portable on chip sensor interfaces based on impedance spectroscopy and biosignal front-end interfaces.
\end{abstract}

Keywords- Analog Low Pass Filter (LPF); impedance spectroscopy; sub-Hz frequency; $G_{m}-C$; low-voltage low-power; programmable filter.

\section{INTRODUCTION}

The growing demand of portable sensing devices for a wide variety of applications has raised the interest in minimizing the power and area consumption of every element that compose these devices. Within such fully integrated front-end interfaces, Low Pass Filters (LPF) are key building blocks extensively used in portable devices to process different physiological signals [1-3], as well as being a critical block in the readout stage of Electrochemical Impedance Spectroscopy (EIS) systems [4, 5].

The motivation of this paper is the design of a low pass filter with a wide range of frequencies, covering the ranges of several biological signals as well as the sub- $\mathrm{Hz}$ ranges of EIS, while at the same time keeping a high dynamic range and low area and power consumption, so that it can be used as a reconfigurable high-performance LPF within portable sensing device platforms capable of measuring a wide variety of signals.

Most of the biological signals recovered from techniques such as electrocardiogram (ECG) [1] or cell evaluation [4], operate at frequencies below the tens of $\mathrm{kHz}$ [6]; in this case LPFs are required to eliminate the contribution of signals at higher frequencies (Fig. 1a). Table I presents a brief review of different biological signals with the standard sensors employed to measure the signals and the frequency range at which they work. For electrochemical impedance spectroscopy, LPFs are employed as DC extractors placed at the end of a readout chain of sensor interfaces, in this case requiring sub-Hz cutoff frequencies, such as in Lock-In Amplifier (LIA) based systems (Fig. 1b).

This work has been partially supported by TEC2015-65750-R (MINECO/FEDER, UE) and UZ2019-TEC-08 (University of Zaragoza).

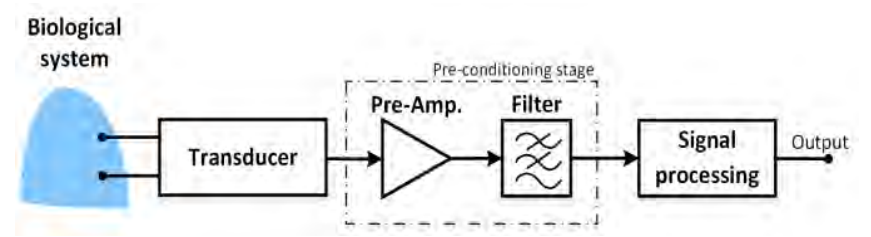

a)

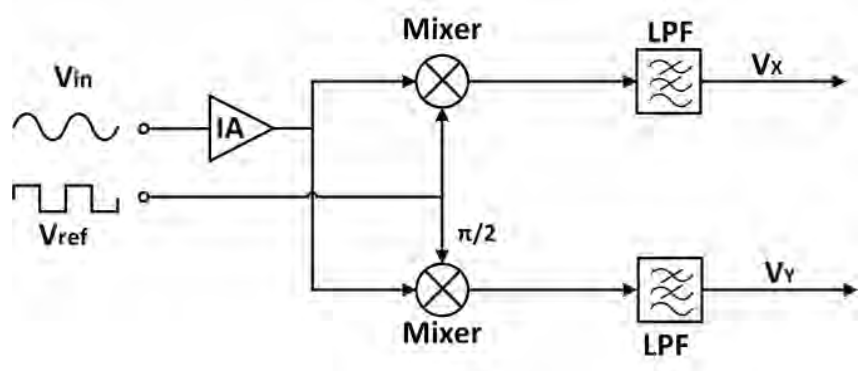

b)

Fig. 1. Block diagram of: a) general-purpose biosignal front-end interface; b) Dual-Phase Lock-in Amplifier.

Lock-in Amplifiers are based on a technique known as phase sensitive detection (PSD), that through synchronous demodulation at a reference frequency $f_{0}$ extracts the amplitude and phase $\left(\mathrm{V}_{\mathrm{x}}\right.$ and $\mathrm{V}_{\mathrm{y}}$ from Fig. $\left.1 \mathrm{~b}\right)$ of very small signals even in noisy environments. This makes it an interesting technique for a wide variety of non-organic markers (gas detection) [5, 7] and biomarkers (proteins, cells, DNA, etc.) $[4,8,9]$

The complexity of designing a fully integrated Low Pass Filter with such a wide frequency range -from sub- $\mathrm{Hz}$ to tens of $\mathrm{kHz}$ - preserving high performance and low-voltage lowpower (LVLP) operation, has led to typically implement these LPFs as external passive RC elements, hindering the achievement of SoC miniaturized solutions, or to design an integrated LPF with fixed $f_{c}$ for each application.

Previously reported works present either very low cutoff frequencies $[10,11]$ or certain range of programmability, but they fail to put together both characteristics: to have a programmable frequency range from the sub- $\mathrm{Hz}$ to the $\mathrm{kHz}$ range, with a low-voltage low-power consumption and a reduced area topology to comply with the requirements of portable devices. 
TABLE I. REVIEW OF BIOLOGICAL SIGNALS AND THEIR RANGE OF OPERATION [6]

\begin{tabular}{ccc}
\hline Biological signal & Frequency range & Standard sensor \\
\hline ECG & $0.01-250$ & Skin electrodes \\
EMG & $10-150$ & $\begin{array}{c}\text { Needle electrodes } \\
\text { Surface or needle } \\
\text { electrodes } \\
\text { Nerve potential }\end{array}$ \\
Dlood flow & DC-20 & $\begin{array}{c}\text { Electromagnetic or } \\
\text { ultrasonic } \\
\text { Microphone }\end{array}$ \\
\hline
\end{tabular}

A review of the literature shows that the most common technique to achieve a fully integrated CMOS LPF is to use a $\mathrm{G}_{\mathrm{m}}-\mathrm{C}$ structure (Fig. 2). To achieve sub-Hz frequencies, $\mathrm{C}$ is maximized (up to $50 \mathrm{pF}$ due to technology limitations) and $\mathrm{G}_{\mathrm{m}}$ minimized. With these values, the transconductance needs to be in the order of $\mathrm{nS}$, requiring transconductance reduction techniques.

In this paper, we present an active $\mathrm{G}_{\mathrm{m}}-\mathrm{C}$ Low Pass Filter integrated in a $180 \mathrm{~nm}$ CMOS technology. It includes two different tuning techniques to adjust the transconductance and therefore, the cutoff frequency of the filter, as well as two different digitally programmable load capacitors $(5 \mathrm{pF}$ and $50 \mathrm{pF}$ ), to further expand the cutoff frequency -in our particular case increasing by an order of magnitude the maximum cutoff frequency-. In this way, a multi-decade frequency tuning low pass filter is proposed covering the ranges of a great number of applications. Besides, it exhibits a high dynamic range, with minimum noise and high input common range, while at the same time satisfies the lowvoltage low-power and minimum area constraints of portable devices, being a very competitive general purpose reconfigurable solution.

The paper is organized as follows. Section II describes the proposed $\mathrm{G}_{\mathrm{m}}-\mathrm{C}$ structure and the techniques used to provide programmability to $f_{c}$. In Section III, post-layout simulation results are summarized. Finally, conclusions are drawn in Section IV.

a)

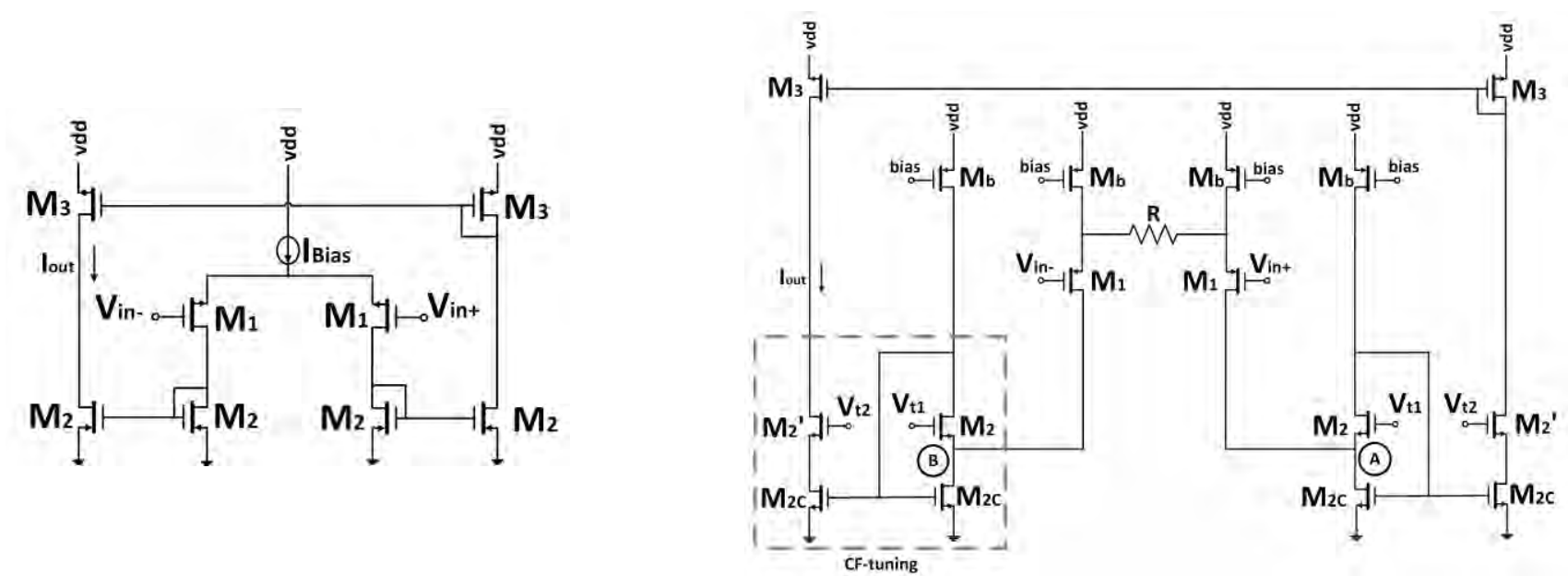

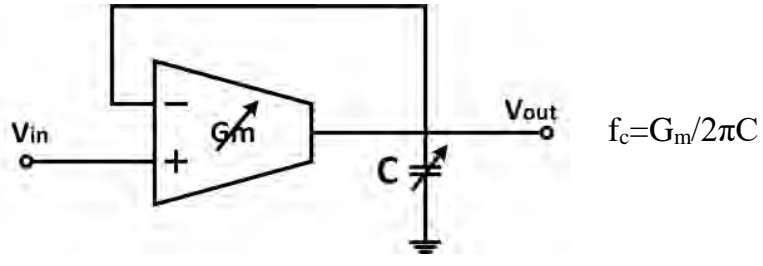

Fig. 2. Single-ended $\mathrm{G}_{\mathrm{m}}-\mathrm{C}$ integrator; both $\mathrm{G}_{\mathrm{m}}$ and $\mathrm{C}$ can be varied to adjust the cutoff frequency.

\section{ACTIVE FILTER STRUCTURE}

In this section, it will be firstly introduced the core of the structure. Then, the two $\mathrm{G}_{\mathrm{m}}$-tuning strategies will be presented together with the full schematic view of the proposed $\mathrm{G}_{\mathrm{m}}-\mathrm{C}$ basic structure.

\section{A. Input stage}

The core structure of this design is a classic mirrored OTA (Fig. 3a) with a PMOS input differential pair degenerated with a fixed resistor $\mathrm{R}$ of $50 \mathrm{k} \Omega$ [12]. The input pair drain nodes are connected to the low impedance nodes A and B, as shown in Fig. 3b, of NMOS high swing cascode current mirrors.

\section{B. Copy factor tuning (CF-tuning)}

The first programmable technique is introduced at the high swing NMOS cascode current mirrors stage made of transistors M2-M2 (Fig. 3b).

By controlling the cascode voltages $\mathrm{V}_{\mathrm{t} 1}$ and $\mathrm{V}_{\mathrm{t} 2}$, it is possible to keep transistors $\mathrm{M} 2_{\mathrm{C}}$ in triode region. Then, by setting $\mathrm{V}_{\mathrm{t} 2} \leq \mathrm{V}_{\mathrm{t} 1}$ the complementary currents generated at the input stage are copied through these current mirrors with an scaling ratio.

\section{Current-Steering technique (CS-tuning)}

The second proposed technique is based on a current steering approach introduced at the M3 output stage of the OTA. For that, a current-steering gain-tuneable $\mathrm{M} 3-\mathrm{M} 3_{\mathrm{C}}$ PMOS high swing cascode current mirror, as shown in Fig. 4, substitutes the M3 PMOS current mirror from Fig. 3b.

b)

Fig. 3. a) Classic Mirrored OTA; b) Modified input stage with CF-tuning. 


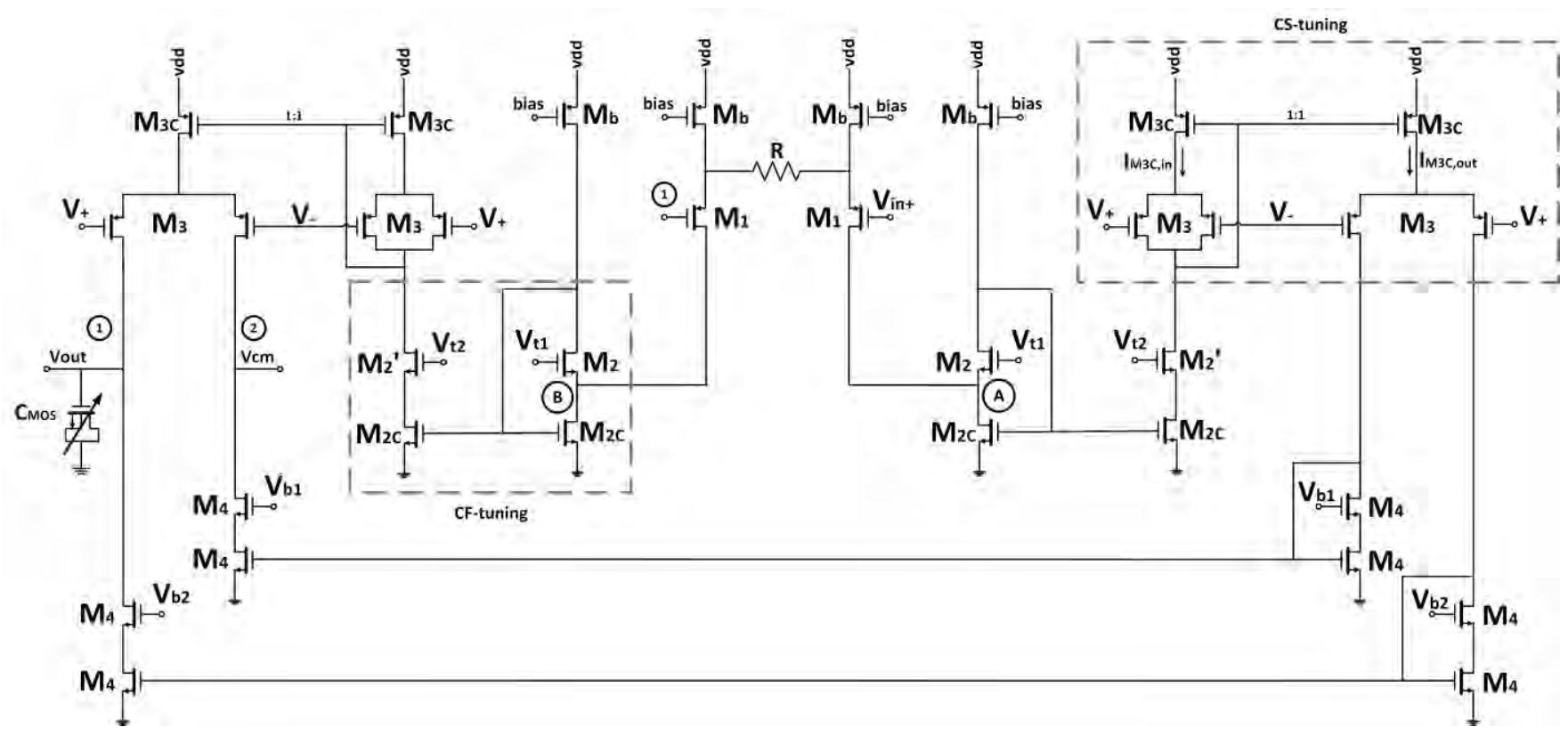

Fig. 4. Complete structure of the $\mathrm{G}_{\mathrm{m}}-\mathrm{C}$ proposal; in grey the tuning techniques applied.

The current copy of transistors $\mathrm{M} 3_{\mathrm{C}}$ has a 1:1 ratio, and as both transistors of the current mirror have the same gate to source voltage, $\mathrm{V}_{\mathrm{gs}}$, and drain to source voltage, $\mathrm{V}_{\mathrm{ds}}$, the current mirror operates properly rendering unity gain current, $\mathrm{I}_{\mathrm{M} 3 \mathrm{c}, \text { out }}=\mathrm{I}_{\mathrm{M} 3 \mathrm{c}, \text { in }}\left(=\mathrm{I}_{\mathrm{M} 3 \mathrm{c}}\right)$.

Transistors M3 are split into two transistors-both at the output and input current mirror branches for symmetry- of equal size driven instead of by a constant $V_{C}$ voltage, by complementary gate voltages $\mathrm{V}_{ \pm}=\mathrm{V}_{\mathrm{C}} \pm \mathrm{V}_{\mathrm{gc}}$ [13], resulting in two output branches, named 1 and 2 . Thus, the output current is divided into two complementary currents $\mathrm{I}_{\text {out }}=\mathrm{I}_{1}+\mathrm{I}_{2}$, with $\mathrm{I}_{1}=(1-\mathrm{k}) \mathrm{I}_{\mathrm{M} 3 \mathrm{c}}$ and $\mathrm{I}_{2}=\mathrm{kI}_{\mathrm{M} 3 \mathrm{c}}$, being $\mathrm{k}$ a fractional value between 0 and 1 dependent on the differential control voltage $\mathrm{V}_{\mathrm{gc}}$. Output 1 is chosen as the output of the unity gain integrator while output 2 is set to $\mathrm{V}_{\mathrm{cm}}$ for symmetry.

The complete schematic of the proposed structure is shown in Fig. 4, highlighted in grey the two techniques employed. Transistor sizes in $(\mu \mathrm{m} / \mu \mathrm{m})$ are $\mathrm{M} 1=6 / 4, \mathrm{M} 2=2 / 4$, $\mathrm{M} 2{ }^{\prime}=4 / 4, \mathrm{M} 2_{\mathrm{C}}=2 / 4, \mathrm{M} 3=3 / 4, \mathrm{M} 3{ }_{\mathrm{C}}=6 / 4, \mathrm{M} 4=0.5 / 4, \mathrm{Mb}=6 / 4$. Notice that M2' is two times M2 as the current through it is $2 \mathrm{I}_{\mathrm{M} 2}$. The voltage supply is $1.8 \mathrm{~V}$, the common mode is set to $0.9 \mathrm{~V}$ and a $50 \mathrm{nA}$ bias current is introduced through a 1:1 current mirror to $\mathrm{Mb}$. Thus, the total power consumption is $1.08 \mu \mathrm{W}$.

\section{POST-LAyOUT SIMULATION RESUltS}

The $\mathrm{G}_{\mathrm{m}}-\mathrm{C}$ structure proposed in Fig. 4 has been designed in a $180 \mathrm{~nm}$ CMOS technology from TSMC. The total active area of the $\mathrm{G}_{\mathrm{m}}-\mathrm{C}$ structure is $0.0156 \mathrm{~mm}^{2}$.

Voltage $\mathrm{V}_{\mathrm{C}}=1.2 \mathrm{~V}$; the tuning voltage $\mathrm{V}_{\mathrm{gc}}$ can be varied from $-100 \mathrm{mV}$ to $170 \mathrm{mV}$ while ensuring a maximum $\mathrm{DC}$ gain error below $0.5 \mathrm{~dB}$. Voltages $\mathrm{V}_{\mathrm{t} 1}$ and $\mathrm{V}_{\mathrm{t} 2}$ are initially set to $0.6 \mathrm{~V}$; then, $\mathrm{V}_{\mathrm{t} 2}$ can be varied from $0.6 \mathrm{~V}$ to $0.35 \mathrm{~V}$.

Fig. 5 shows the different cutoff frequencies achieved over all the $\mathrm{V}_{\mathrm{gc}}$ range with $\mathrm{V}_{\mathrm{t} 2}$ equal to $0.35 \mathrm{~V}, 0.4 \mathrm{~V}$ and $0.6 \mathrm{~V}$, at both maximum $(50 \mathrm{pF})$ and minimum $(5 \mathrm{pF})$ load capacitance. The cutoff frequency, with $\mathrm{C}_{\mathrm{L}}=50 \mathrm{pF}$, ranges from $220 \mathrm{mHz}\left(\mathrm{V}_{\mathrm{gc}}=144 \mathrm{mV}, \mathrm{V}_{\mathrm{t} 2}=0.35 \mathrm{~V}\right)$ up to $3.72 \mathrm{kHz}$
$\left(\mathrm{V}_{\mathrm{gc}}=-100 \mathrm{mV}, \mathrm{V}_{\mathrm{t} 2}=0.6 \mathrm{~V}\right)$. This maximum cutoff frequency can be increased up to $39.1 \mathrm{kHz}$ by reducing the load capacitance down to $5 \mathrm{pF}$.

From Fig. 5 a thick/fine-tuning relationship between both CS/CF-tuning techniques can be appreciated. Thick-tuning refers to the CS-technique: through the $\sim 270 \mathrm{mV}$ range of $\mathrm{V}_{\mathrm{gc}}$ is possible to adjust the cutoff frequency of the filter to the order of magnitude of the target frequency. Thick-tuning as shown in Fig. 6, is provided by the CF-technique: with the $\sim 250 \mathrm{mV}$ range of $\mathrm{V}_{\mathrm{t} 2}$, it is possible to tune the cutoff frequency over an order of magnitude, accurately adjusting the cutoff frequency through a smaller step $(\mathrm{Hz} / \mathrm{mV})$.

A clear visualization of this thick/thin relationship comes from the estimation of the step $(\mathrm{Hz} / \mathrm{mV})$ for each of the tunings. In Fig. 5 the $f_{c}$ ranges from $3.72 \mathrm{kHz}$ down to $0.69 \mathrm{~Hz}\left(\mathrm{~V}_{\mathrm{t} 2}=0.6 \mathrm{~V}, \mathrm{C}_{\mathrm{L}}=50 \mathrm{pF}\right)$, for a $\mathrm{V}_{\mathrm{gc}}$ range of $\sim 270 \mathrm{mV}$, giving a $\sim 13.8 \mathrm{~Hz} / \mathrm{mV}$ step. The thin-tuning step, from Fig. 6 , is $0.54 \mathrm{~Hz} / \mathrm{mV} \quad\left(\mathrm{V}_{\mathrm{gc}}=74 \mathrm{mV}\right)$ and $0.01 \mathrm{~Hz} / \mathrm{mV}$ $\left(\mathrm{V}_{\mathrm{gc}}=144 \mathrm{mV}\right)$.

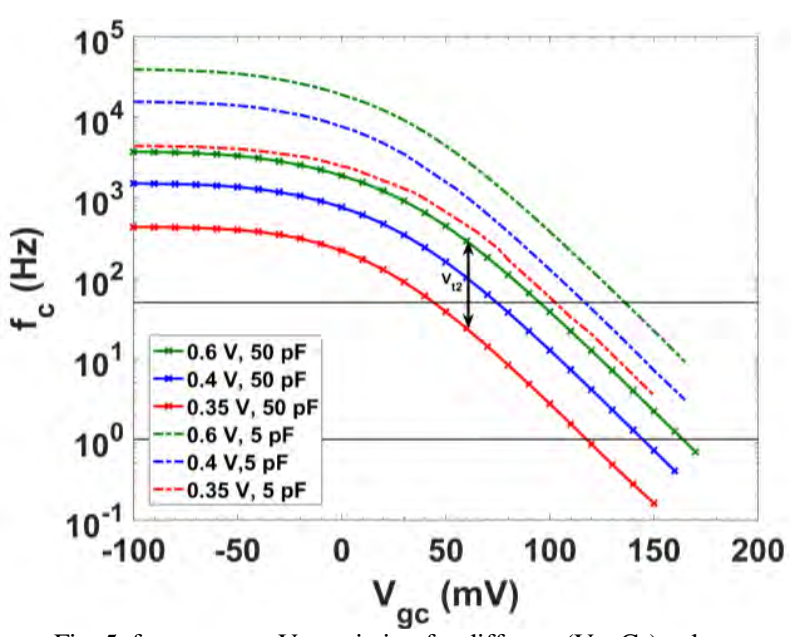

Fig. 5. $f_{c}$ range over $V_{g c}$ variation for different $\left(V_{t 2}, C_{L}\right)$ values. 


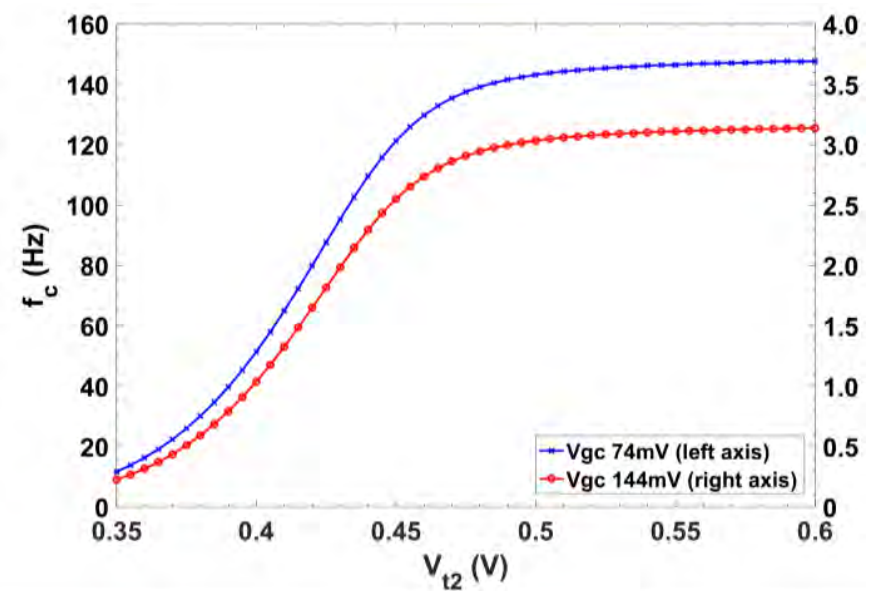

Fig. 6. Filter $f_{c}$ tunability for different $V_{t 2}$ values with $V_{g c}$ fixed. Left axis for $\mathrm{V}_{\mathrm{gc}} 74 \mathrm{mV}$ (blue), and right axis for $\mathrm{V}_{\mathrm{gc}} 144 \mathrm{mV}$ (red).

In order to characterize the proposed filter, we are going to focus on two different cutoff frequencies, $1 \mathrm{~Hz}$ and $50 \mathrm{~Hz}$, with a $\mathrm{C}_{\mathrm{L}}=50 \mathrm{pF}$. As the same $\mathrm{f}_{\mathrm{c}}$ can be achieved through different combinations of $\left(\mathrm{V}_{\mathrm{t} 2}, \mathrm{~V}_{\mathrm{gc}}\right)$, it has been characterized for both, $\mathrm{V}_{\mathrm{t} 2}$ maximum and minimum $(0.6 \mathrm{~V}$ and $0.35 \mathrm{~V})$. Table II shows post-layout simulation results for those two frequencies for the static input-output characteristic (ICMR), the total harmonic distortion (THD), integrated noise and dynamic range (DR).

The static input-output characteristic (ICMR) is shown in Fig. 7. Note that MOS capacitors require a minimum voltage to keep the capacitance, limiting the minimum output voltage to $\geq 0.45 \mathrm{~V}$. While the total harmonic distortion (THD) is presented in Fig. 8, for both cutoff frequencies $1 \mathrm{~Hz}$ and $50 \mathrm{~Hz}$. With an input signal of frequency $\mathrm{f}_{\mathrm{in}}=\mathrm{f}_{\mathrm{c}} / 5$.

TABLE II. SIMULATION RESULTS COMPARISON FOR CUTOFF FREQUENCIES $1 \& 50 \mathrm{~Hz}$

\begin{tabular}{ccccc}
\hline $\mathbf{f}_{\mathbf{c}}(\mathbf{H z})$ & \multicolumn{3}{c}{$\mathbf{1}$} & \multicolumn{2}{c}{$\mathbf{5 0}$} \\
\hline$\left(\mathrm{V}_{\mathrm{gc}}, \mathrm{V}_{\mathrm{t} 2}\right)$ & $\begin{array}{c}(118 \mathrm{mV}, \\
0.35 \mathrm{~V})\end{array}$ & $\begin{array}{c}(164 \mathrm{mV}, \\
0.6 \mathrm{~V})\end{array}$ & $\begin{array}{c}(45 \mathrm{mV}, \\
0.35 \mathrm{~V})\end{array}$ & $\begin{array}{c}(96 \mathrm{mV}, \\
0.6 \mathrm{~V})\end{array}$ \\
$\begin{array}{c}\text { ICMR }(\mathrm{V}) \\
\text { Linearity }\left(\mathrm{V}_{\mathrm{pp}}\right) \\
(\mathrm{THD} \leq 1 \%)\end{array}$ & 0.706 & 0.559 & 1.24 & 0.642 \\
$\begin{array}{c}\text { Input noise } \\
\left(\mu \mathrm{V}_{\mathrm{rms}}\right)\end{array}$ & 131 & $59.8 \mathrm{~m}-1.38$ & $52.8 \mathrm{~m}-1.45$ & $52.8 \mathrm{~m}-1.45$ \\
$\mathrm{DR}(\mathrm{dB})$ & 65.6 & 73.0 & 67.4 & 71.9 \\
\hline
\end{tabular}

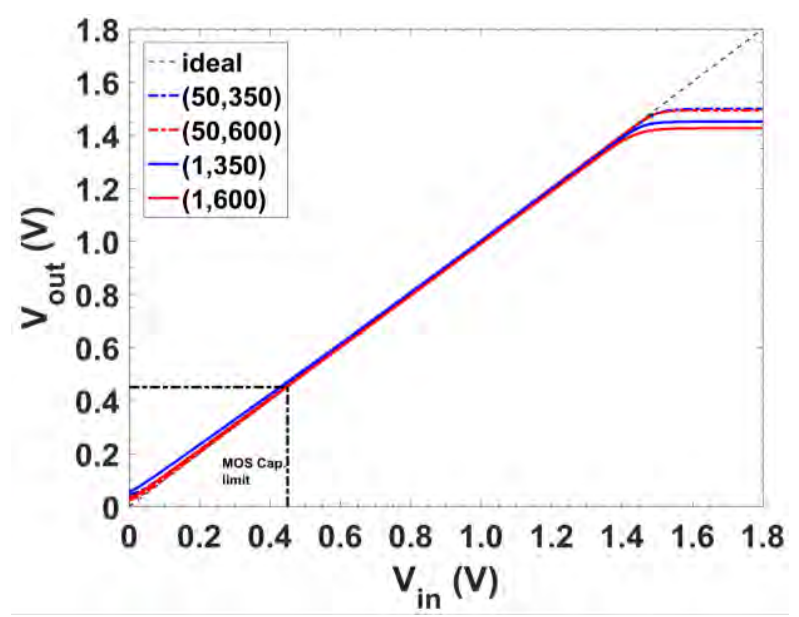

Fig. 7. $V_{\text {in }}-V_{\text {out }}$ characteristic for different $\left(f_{c}, V_{t 2}\right)$ values.
To adjust de cutoff frequency, the methodology followed is: first approximate through $\mathrm{V}_{\mathrm{gc}}$ (thick-tuning) with $\mathrm{V}_{\mathrm{t} 2} \approx 0.4 \mathrm{~V}$. Then, $\mathrm{V}_{\mathrm{t} 2}$ (thin-tuning) is modified to improve the accuracy over the target frequency.

In order to optimize the performance, among the different possible combinations of $\left(\mathrm{V}_{\mathrm{gc}}, \mathrm{V}_{\mathrm{t} 2}\right)$ that provide the same $\mathrm{f}_{\mathrm{c}}$, those with the highest $\mathrm{V}_{\mathrm{t} 2}$ and lowest $\mathrm{V}_{\mathrm{gc}}$ provide the best performance in terms of DR and input noise. This is because as $\mathrm{V}_{\mathrm{t} 2}$ increases and $\mathrm{V}_{\mathrm{gc}}$ decreases, the OTA proposed (Fig. 4) becomes more symmetrical as the value of $V_{t 2}$ approaches $\mathrm{V}_{\mathrm{t} 1}$ and $\mathrm{V}_{ \pm}$approaches $\mathrm{V}_{\mathrm{c}}$.

Thanks to the wide tunability of the system, it is possible to compensate any variation that may appear over the $f_{c}$ due to PVT (Process, Voltage and Temperature) variations.

If the application requires it, the frequency ranges can be further extended with simple modifications to the circuit, such as $C_{L}$ reduction to move up the cutoff frequency. The same can be achieved by an increase on the bias current. In addition, an increase on $R$ would decrease the overall $G_{m}$ at the expense of higher noise.

Finally, the main parameters are summarized in Table III. This work presents a wide tuneable cutoff frequency range, preserving low power and area consumption while higher dynamic range and ICMR are observed compared with previously reported works with similar cutoff frequencies.

\section{CONCLUSIONS}

In this paper, a low pass filter with tuneable cutoff frequency that spans over several orders of magnitude and capable of achieving sub-Hz frequencies has been presented. Two tuning techniques implemented as thick/fine-tuning allows for an accurate selection of the cutoff frequency, while at the same time provides competitive performances in terms of area-power consumption, dynamic range and inputoutput DC characteristic. All of this makes the proposed filter highly suitable for portable on chip sensor interfaces based on impedance spectroscopy and biosignal front-end interfaces.

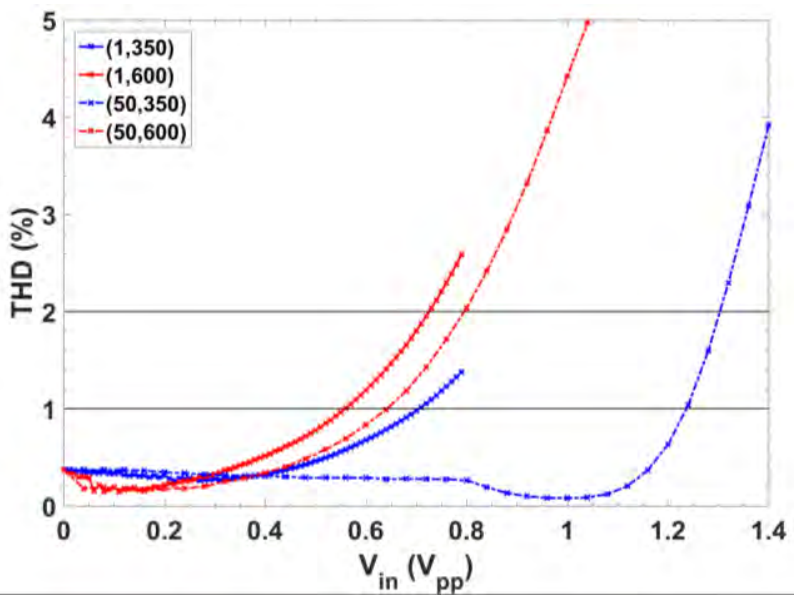

Fig. 8. THD vs input signal amplitude (peak-to-peak) for $\mathrm{f}_{\mathrm{in}}=\mathrm{f}_{\mathrm{d}} / 5$ for different $\left(\mathrm{f}_{\mathrm{c}}, \mathrm{V}_{\mathrm{t} 2}\right)$ values. 
TABLE III

$\mathrm{G}_{\mathrm{M}}-\mathrm{C}$ PERFORMANCE COMPARISON WITH SIMILAR WORKS

\begin{tabular}{|c|c|c|c|c|c|}
\hline Parameter & This work & [3] & [11] & [14] & [15] \\
\hline Results & Post-layout & Exp. & Exp. & Post-layout & Exp. \\
\hline Technology $(\mu \mathrm{m})$ & 0.18 & 0.35 & 0.35 & 0.18 & 0.35 \\
\hline Order & 1 & 4 & 1 & 2 & 2 \\
\hline $\mathrm{V}_{\text {supply }}(\mathrm{V})$ & 1.8 & 0.6 & 1 & 1 & 1.8 \\
\hline $\mathrm{I}_{\text {Bias }}(\mathrm{nA})$ & 50 & $1.5-4.5$ & $0.2 / 1-4 / 20^{(\mathrm{d})}$ & $0.25-25$ & $14.9-182.3$ \\
\hline $\mathrm{I}_{\text {Total }}(\mathrm{nA})$ & 600 & $\mathrm{NA}^{*}$ & NA & NA & $60-730$ \\
\hline Power $(\mu \mathrm{W})$ & 1.08 & $0.0009-0.0027$ & $0.005^{(\mathrm{e})}$ & $0.009-0.9$ & $0.1-1.31$ \\
\hline Area $\left(\mathrm{mm}^{2}\right)$ & 0.0156 & 0.168 & 0.07 & 0.0388 & 0.12 \\
\hline $\mathrm{C}_{\text {Total }}(\mathrm{pF}) /$ pole & 50 & NA & 40 & 78 & NA \\
\hline Tuneable & Thick/fine-tuning & $\mathrm{I}_{\text {bias }}$ & $I_{\text {bias }}$ & $I_{\text {bias }}$ & $\mathrm{I}_{\text {bias }}$ \\
\hline $\mathrm{f}_{\mathrm{c}}(\mathrm{Hz})$ & $0.22-39.1 \mathrm{k}$ & $101-272$ & $0.002-90$ & $0.73-76$ & $2 \mathrm{k}-20 \mathrm{k}$ \\
\hline $\operatorname{ICMR}(\mathrm{V})$ & $0.06-1.38 ; 0.05-1.45^{\text {(a) }}$ & NA & $0.4-0.55$ & NA & NA \\
\hline Linearity $\left(\mathrm{V}_{\mathrm{pp}}\right) \mathrm{THD} @ 1 \%$ & $0.706-0.559 ; 1.237-0.642^{(b)}$ & NA & $0.14 @ \mathrm{f}_{\mathrm{c}}=\mathrm{f}_{\mathrm{in}}=1 \mathrm{~Hz}$ & $0.54 @ \mathrm{f}_{\mathrm{c}}=0.73 \mathrm{~Hz}$ & $0.216 ; 0.294$ \\
\hline Input noise $\left(\mu \mathrm{V}_{\mathrm{rms}}\right)$ & $133-44.3 ; 186-57.3^{(\mathbf{b}, \mathbf{c})}$ & $46.6-46.8$ & $32 @ \mathrm{f}_{\mathrm{c}}=1 \mathrm{~Hz}$ & $177.4 @ \mathrm{f}_{\mathrm{c}}=0.73 \mathrm{~Hz}$ & $86.3 ; 84.3$ \\
\hline $\mathrm{DR}(\mathrm{dB})$ & $65.5-73.0 ; 67.4-72.0^{(\mathrm{b})}$ & 47 & 64 & $>64$ & $58.9 ; 61.8$ \\
\hline
\end{tabular}

$* \mathrm{NA}=$ Not Available. ${ }^{(\mathrm{a})}$ worst case for $\mathrm{f}_{\mathrm{c}}=1 \& 50 \mathrm{~Hz} ;{ }^{\left({ }^{(b)}\right.} \mathrm{V}_{\mathrm{t} 2}=0.35 \& 0.6 \mathrm{~V}$ for $\mathrm{f}_{\mathrm{c}}=1 \& 50 \mathrm{~Hz}$; ${ }^{(\mathrm{c})}$ integrated noise from $10 \mathrm{mHz}$ to $10 \mathrm{kHz}$; ${ }^{(\mathrm{d})}$ It has 2 different bias currents; ${ }^{(\mathrm{e})}$ Power for nominal cutoff frequency without external clock and tuning.

\section{REFERENCES}

[1] Shuenn-Yuh Lee and Chih-Jen Cheng, "Systematic Design and Modeling of A OTA-C Filter for Portable ECG Detection”. IEEE Transactions on Biomedical Circuits and Systems, vol. 3, no. 1, pp. 53-64, Feb. 2009

[2] S. Lee, C. Wang and Y. Chu, "Low-Voltage OTA-C Filter With an Area- and Power-Efficient OTA for Biosignal Sensor Applications," in IEEE Transactions on Biomedical Circuits and Systems, vol. 13, no. 1, pp. 56-67, Feb. 2019

[3] C. Sawigun and S. Thanapitak, "A 0.9-nW, 101-Hz, and 46.3 $\mu$ VrmsIRN Low-Pass Filter for ECG Acquisition Using FVF Biquads," in IEEE Transactions on Very Large Scale Integration (VLSI) Systems, vol. 26, no. 11, pp. 2290-2298, Nov. 2018.

[4] A.R. Cardoso, G. Cabral-Miranda, A. Reyes-Sandoval, M.F Bachmann, M.G.F. Sales, "Detecting circulating antibodies by controlled surface modification with specific target proteins: Application to malaria", Biosens. Bioelectron. 2017, 91, 833-841.

[5] P.M. Maya-Hernández, M.T. Sanz-Pascual and B. Calvo. UltralowPower Synchronous Demodulation for Low-Level Sensor Signal Detection. IEEE TIM. 2018, pp. 1-10.

[6] J.G.Webster, "Medical Instrumentation: Application and Design". Hoboken, NJ, USA: Wiley, 2009.

[7] F. Badets, J.-G. Coutard, P. Russo, E. Dina, A. Glière and S Nicoletti. A $1.3 \mathrm{~mW}$, 12-bit Lock-In Amplifier Based Readout Circuit Dedicated to Photo-Acoustic Gas Sensing. IEEE Sensors 2016, Orlando, FL, pp. 1-3.

[8] H. Li, X. Liu, L. Li, X. Mu, R. Genov and A.j. Mason. CMOS Electrochemical Instrumentation for Biosensor Microsystems: A Review. Sensors 2017, 17, 74.
[9] M.O. Shaikh, B. Srikanth, Z. Pei-Yu and C. Cheng-Hsin. Impedimetric Immunosensor Utilizing Polyaniline/Gold Nanocomposite-Modified Screen-Printed Electrodes for Early Detection of Chronic Kidney Disease. Sensors 2019, 19, 3990.

[10] R. Rieger, A. Demosthenous, and J. Taylor. "A 230-nW 10-s Time Constant CMOS Integrator for an Adaptive Nerve Signal Amplifier", IEEE J. Solid-State Circuits, vol. 39, no. 11, pp. 1968-1975, Nov. 2004.

[11] E. Rodriguez-Villegas, A. J. Casson, and P. Corbishley. "A sub-Hertz nanopower low pass filter", IEEE Trans. Circuits Systems II, Exp. Briefs, vol. 58, pp. 351-355, 2011.

[12] M. Subhash, J. Ramírez-Angulo, A.J. López-Martín, R.G. Carvajal, "Wide gm Adjustment Range Highly Linear OTA with Programmable Mirrors Operating in Triode Mode", IEEE International Midwest Symposium on Circuits and Systems (MWSCAS), 2005.

[13] J. Ramírez-Angulo, S. R. Sudha Gariemlla, and A. Lopez-Martin. "New Gain Programmable Current Mirrors Based on Current Steering", IEEE International Midwest Symposium on Circuits and Systems (MWSCAS), 2006.

[14] C. Sawigun and W. A. Serdijn, "A modular transconductance reduction technique for very low-frequency Gm-C filters," 2012 IEEE International Symposium on Circuits and Systems, Seoul, 2012, pp. 1183-1186.

[15] S. Peng et al., "A Power-Efficient Reconfigurable OTA-C Filter for Low-Frequency Biomedical Applications," in IEEE Transactions on Circuits and Systems I: Regular Papers, vol. 65, no. 2, pp. 543-555, Feb. 2018. 